\title{
Brief communication \\ "Importance of slope-induced error correction in volume change estimates from radar altimetry"
}

\author{
R. T. W. L. Hurkmans, J. L. Bamber, and J. A. Griggs \\ Bristol Glaciology Centre, School of Geographical Sciences, University of Bristol, Bristol, UK \\ Correspondence to: R. T. W. L. Hurkmans (ruud.hurkmans@bristol.ac.uk) \\ Received: 16 December 2011 - Published in The Cryosphere Discuss.: 17 January 2012 \\ Revised: 20 March 2012 - Accepted: 24 March 2012 - Published: 3 April 2012
}

\begin{abstract}
In deriving elevation change rates $(\mathrm{d} H / \mathrm{d} t)$ from radar altimetry, the slope-induced error is usually assumed to cancel out in repeat measurements. These measurements, however, represent a location that can be significantly further upslope than assumed, causing an underestimate of the basin-integrated volume change. In a case-study for the fastflowing part of Jakobshavn Isbræ, we show that a relatively straightforward correction for slope-induced error increases elevation change rates by up to several metres per year and significantly reduces the volume change error with respect to laser altimetry for the area of interest.
\end{abstract}

\section{Introduction}

Several sources of uncertainty affect measurements of ice sheet surface elevation derived from satellite radar altimetry (SRA; e.g. Brenner et al., 2007; Bamber, 1994). Potentially the largest one, referred to as the slope-induced error (Brenner et al., 1983), is caused by regional surface slopes. For narrow, fast-flowing outlet glaciers, the lowest surface may not be sampled at all (see Fig. 9 of Thomas et al., 2008), however these are often the areas that show the largest elevation changes (Pritchard et al., 2009). The radar return signal does not originate from the point directly underneath the satellite (nadir), but from the closest point to the satellite, which can be significantly displaced upslope from nadir. For a $1^{\circ}$ slope and a satellite altitude of $800 \mathrm{~km}$, which is not unusual at the ice sheet margin, the displacement between nadir and the actual measurement location is about $14 \mathrm{~km}$, and the vertical error is about $120 \mathrm{~m}$. Using a regional slope estimate, it is relatively straightforward to relocate the measurement to its correct location (Bamber, 1994). When elevation change is concerned, however, it is usually assumed that the slope-induced error remains constant and the effect cancels (Thomas et al., 2008). While the error in the vertical is indeed the same for repeating elevation measurements, the location of the measured elevation change rate will still be displaced from its true position. Here, we show that the integrated volume change can be significantly underestimated, because elevation changes that are measured at an upslope location are incorrectly located closer to the margin.

\section{Data}

To demonstrate the effect of correcting for slope-induced error, we use data from the radar altimeter (RA-2) on ESA's Envisat satellite, that was launched in 2002. It continues the SRA time series from ERS-1 and ERS-2 and is in a similar orbit with an altitude of about $800 \mathrm{~km}$, a repeat period of 35 days, and a latitudinal coverage up to $81.5^{\circ}$. We use Envisat cross-over clusters (Li and Davis, 2008) from which we derive average elevation change rates for 2003-2006. The selected study area is the fast-flowing region of Jakobshavn Isbræ, Greenland's largest outlet glacier, located on the southwest coast. Since about 1998, it has been accelerating and thinning significantly (Joughin et al., 2008), and has been densely surveyed by airborne laser altimetry (ATM; Krabill et al., 2004).

We use airborne (ATM) and spaceborne (ICESat) laser altimetry data as a validation dataset. Elevations from these data sources do not suffer from the same slope-induced error 


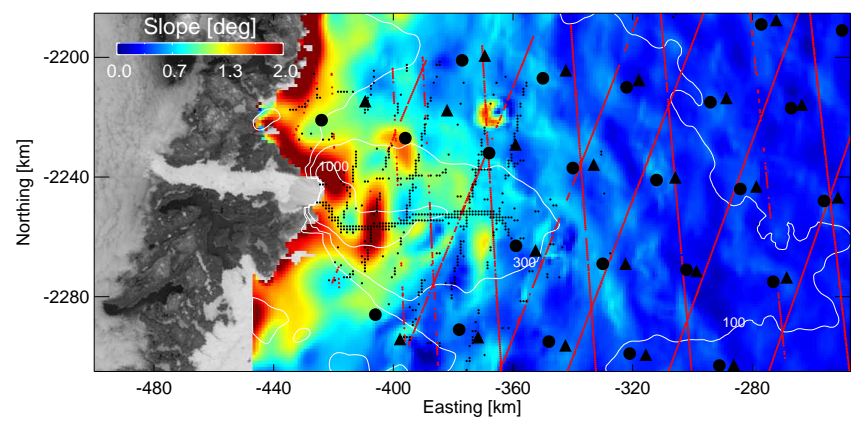

Fig. 1. Slope from Bamber et al. (2001), plotted over a MODIS image from June 2002. Also uncorrected (large black dots) and corrected (black triangles) locations of Envisat cross-over clusters, ICESat tracks (red dots), and ATM flight lines (small black dots) are shown. Velocity is shown as 100,300 , and $1000 \mathrm{~m} \mathrm{yr}^{-1}$ contours.

as they have a small footprint with known pointing: $\approx 60 \mathrm{~m}$ for ICESat (Zwally et al., 2002) and 1-2 m for ATM (Krabill et al., 2002). Elevation change rates for 2003-2006 (consistent with Envisat) were derived from ICESat using the "plane" method (Howat et al., 2008). A plane is fitted through data from several near-repeat tracks. For each plane, which is typically about $700 \mathrm{~m}$ long and a few hundred metres wide, two-directional slopes and a temporal elevation change rate $\mathrm{d} H / \mathrm{d} t$ are fitted using multivariate linear regression (Moholdt et al., 2010). A regression is only performed if a plane has at least 10 points from four different tracks that span at least a year. Prior to the regression, outliers (outside $2 \sigma)$ are removed, and only elevation changes with an associated standard error on $\mathrm{d} H / \mathrm{d} t$ of less than $0.50 \mathrm{~m} \mathrm{yr}^{-1}$ are considered. ATM footprints were preprocessed and averaged over two $150 \mathrm{~m}$ platelets on each side of the plane (Krabill et al., 2002). We used a similar method as outlined above to derive 2003-2006 elevation change rates from all available flight lines, but instead of platelets, $1 \mathrm{~km}$ pixels were used.

Other datasets that are employed here are a $1 \mathrm{~km}$ digital elevation model (Bamber et al., 2001) from which slope and aspect are derived, and an ice sheet velocity mosaic used for interpolation. The velocity field was derived by Joughin et al. (2010) from a combination of radar interferometry and speckle tracking using RADARSAT- 2 data from the winters 2000-2001, 2005-2006, and 2007-2008. Figure 1 shows the slope, as well as locations of Envisat cross-over points, ICESat tracks, ATM flight lines, and velocity contours for the fast-flowing part of Jakobshavn Isbræ.

\section{Methodology}

The slope-induced error is schematically illustrated in Fig. 2a by a range measurement $R$ to an inclined surface with slope $\alpha$ and aspect $\beta$. The measurement location is displaced from nadir by a horizontal distance $D$. Three correction methods for the range exist (Bamber, 1994). First, the di- rect method corrects the range measured at nadir (corrected range $R_{\mathrm{c}}=R / \cos (\alpha)$ ). The second method, the relocation method, corrects $R$ to $R_{\mathrm{c}}$, where $R_{\mathrm{c}}$ is now the range to the point closest to the satellite (now $R \cos (\alpha)$ ), and displaces the location by $R \sin (\alpha)$. The intermediate method, finally, finds the location where $R=R_{\mathrm{c}}$, and relocates the measurement to that point (Remy et al., 1989). When one is interested in elevation changes, errors in the vertical cancel out, but measurements are still located at the wrong locations. This can lead to underestimation of area-integrated volume changes as $\mathrm{d} H / \mathrm{d} t$ values obtained by radar altimetry are actually located further upslope than assumed (Fig. 2). For cross-over analyses, where $\mathrm{d} H / \mathrm{d} t$ is derived for locations where ascending and descending tracks cross each other, a two-dimensional correction should be applied. The displacement $D$ is given by $D=E \sin (\alpha) \cos (\alpha)$, where $E$ is the satellite altitude, equivalent (but not necessary equal) to $R_{\mathrm{c}}$ in Fig. 2a, and $800 \pm 20 \mathrm{~km}$ for Envisat. Sensitivity to variations in the orbit altitude is small: a sensitivity experiment indicated that, at $1^{\circ}$ slope, a $40 \mathrm{~km}(5 \%)$ range in altitude causes a $\approx 5 \%$ range in horizontal displacement with respect to the displacement for an altitude of $800 \mathrm{~km}$. Sensitivity to slope angle is about the same (a $5 \%$ range in slope causes a $\approx 5 \%$ range in horizontal displacement); therefore ideally contemporaneous estimates of slope should be used. The direction of displacement is opposite to the slope aspect $\beta$, which is the direction of the steepest downward slope. If $\beta$ is defined as 0 radians for north and increasing clockwise to $2 \pi$ radians, the relocation in $\mathrm{x}$ and $\mathrm{y}$ directions are given by $d X=D \sin (\beta-\pi)$ and $d Y=D \cos (\beta-\pi)$. Although small-scale undulations can also cause error (Bamber and Gomez-Dans, 2005), we use average slope and aspect over a $100 \mathrm{~km}^{2}$ area centered on the nadir location to correct for regional slope, as $10 \mathrm{~km}$ is the approximate length scale of the expected displacement.

We illustrate the effect of the correction on volume change using a hypothetical testcase. We simulated a $100 \times 100 \mathrm{~km}$ surface with a slope increasing linearly toward lower elevations from 0.5 to 1.5 degrees (Fig. $2 \mathrm{~b}$ ). Synthetic $\mathrm{d} H / \mathrm{d} t$ data, ranging linearly from $2 \mathrm{~m} \mathrm{yr}^{-1}$ at $1.5^{\circ}$ slope to $1 \mathrm{~m} \mathrm{yr}^{-1}$ at $0.5^{\circ}$ slope, are evenly spaced at $10 \mathrm{~km}$ intervals. $\mathrm{d} H / \mathrm{d} t$ data coverage is assumed to extend linearly beyond the domain, so the correction displaces data points "into" the domain. A full $1 \mathrm{~km}$ resolution $\mathrm{d} H / \mathrm{d} t$ field is obtained using inverse distance interpolation. In Fig. 2c, all data locations are corrected for slope-induced error, enlarging the area with the largest $\mathrm{d} H / \mathrm{d} t$. For this particular testcase, the relative difference in volume change (i.e. between Fig. $2 b$ and c) is $10.4 \%$. It should be noted that $\mathrm{d} H / \mathrm{d} t$ values are relatively modest compared to Jakobshavn Isbræ.

\section{Results}

Figure 3a shows a scatterplot of $\mathrm{d} H / \mathrm{d} t$ from Envisat cross-over clusters versus $\mathrm{d} H / \mathrm{d} t$ from interpolation of 

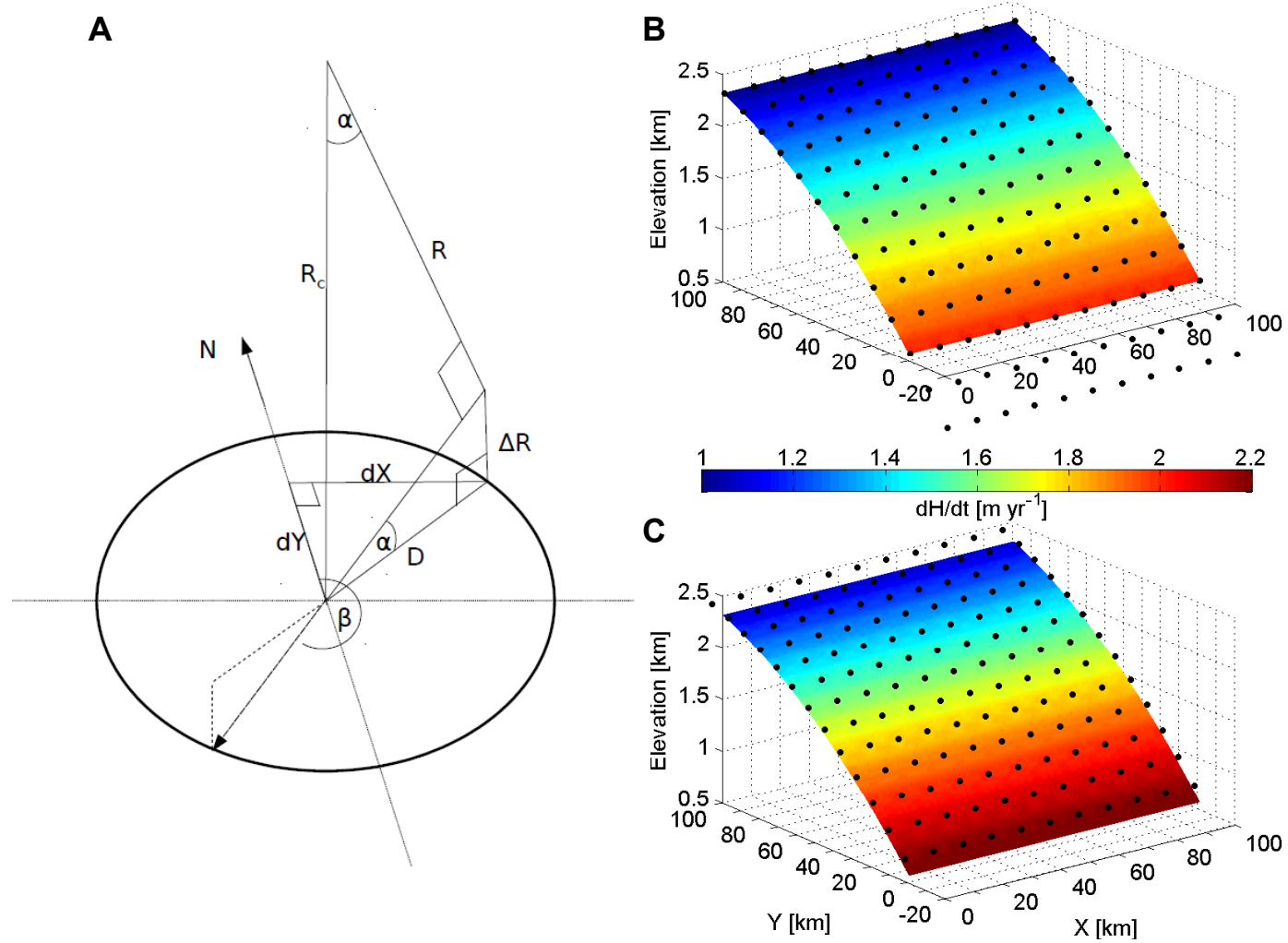

Fig. 2. (A) Geometry of the two-dimensional slope-induced error correction. $\alpha$ and $\beta$ are, respectively, the slope and aspect (both in radians), $R$ is the range $(\approx 800 \mathrm{~km}), R_{c}$ the corrected range and $\Delta R$ the vertical correction. $D$ is the horizontal distance over which a cross-over point is displaced, and $d X$ and $d Y$ are its components in the $\mathrm{x}$ - and y-direction. (B) shows $\mathrm{d} H / \mathrm{d} t$ on a synthetic slope without correction for slope-induced error, and (C) with correction. Black dots show $\mathrm{d} H / \mathrm{d} t$ data locations without $(\mathbf{B})$ and with $(\mathbf{C})$ correction.

ATM/ICESat, for both the uncorrected and the corrected Envisat locations. Interpolation was conducted using kriging with external drift (KED), which uses the spatial pattern of ice velocity as a proxy for that of $\mathrm{d} H / \mathrm{d} t$, i.e. a steep spatial gradient in velocity leads to a similarly steep gradient in $\mathrm{d} H / \mathrm{d} t$ in the absence of local $\mathrm{d} H / \mathrm{d} t$ measurements. The method is described in detail elsewhere (Hurkmans et al., 2012), where they found that for Jakobshavn Isbræ, KED results in more realistic $\mathrm{d} H / \mathrm{d} t$ patterns (with respect to ATM) than other methods investigated. The sparsity of Envisat data is illustrated by the fact that there are only 23 Envisat crossover clusters in the study area. Uncorrected values are generally corrected towards the ATM/ICESat values effectively, sometimes with elevation change corrections of several metres per year. There is still, however, considerable noise in the corrected scatterplot, because (i) the correction only corrects Envisat data for the footprint-average slope and not for smaller scale undulations, (ii) interpolated values from ATM/ICESat were used because Envisat and ATM/ICESat footprints never exactly overlap, and (iii) various differences between radar and laser altimetry, such as footprint size, orbit errors, and the backscattering correction necessary for radar altimetry. The effectiveness of the correction is illustrated by the correlation coefficient which increases from 0.35 to 0.88 after the correction for slope-induced error.

Interpolated $\mathrm{d} H / \mathrm{d} t$ values are shown in Fig. $3 \mathrm{~b}$ and c. In Fig. 3b, a transect is shown constructed by calculating the average north-south $\mathrm{d} H / \mathrm{d} t$ within the $300 \mathrm{~m} \mathrm{yr}^{-1}$ velocity contour for each $1 \mathrm{~km}$ pixel moving east from the grounding zone. The difference in thinning rates between corrected and uncorrected Envisat data increases from about $0.4 \mathrm{~m} \mathrm{yr}^{-1}$ at $80 \mathrm{~km}$ from the grounding zone to about $2.5 \mathrm{~m} \mathrm{yr}^{-1}$ at $5 \mathrm{~km}$. A three kilometre zone adjacent to the presumed grounding line was not taken into account because of uncertainty in its location (Hurkmans et al., 2012). After correction for slope-induced error, interpolated thinning rates are both larger and more widespread. This can be seen in Fig. 3c, where the difference between interpolated $\mathrm{d} H / \mathrm{d} t$ values with and without slope-correction are shown. The effect of the correction can also be quantified by calculating the integrated volume change for the area. The volume loss for the area enclosed by the $100 \mathrm{~m} \mathrm{yr}^{-1}$ velocity contour is $8.6 \mathrm{~km}^{3} \mathrm{yr}^{-1}$ for uncorrected Envisat, $11.4 \mathrm{~km}^{3} \mathrm{yr}^{-1}$ for corrected Envisat, and $19.6 \mathrm{~km}^{3} \mathrm{yr}^{-1}$ for ATM/ICESat. With respect to ATM/ICESat, the error of the Envisat based volume change rate thus reduces from $-56 \%$ to $-42 \%$. For the area 

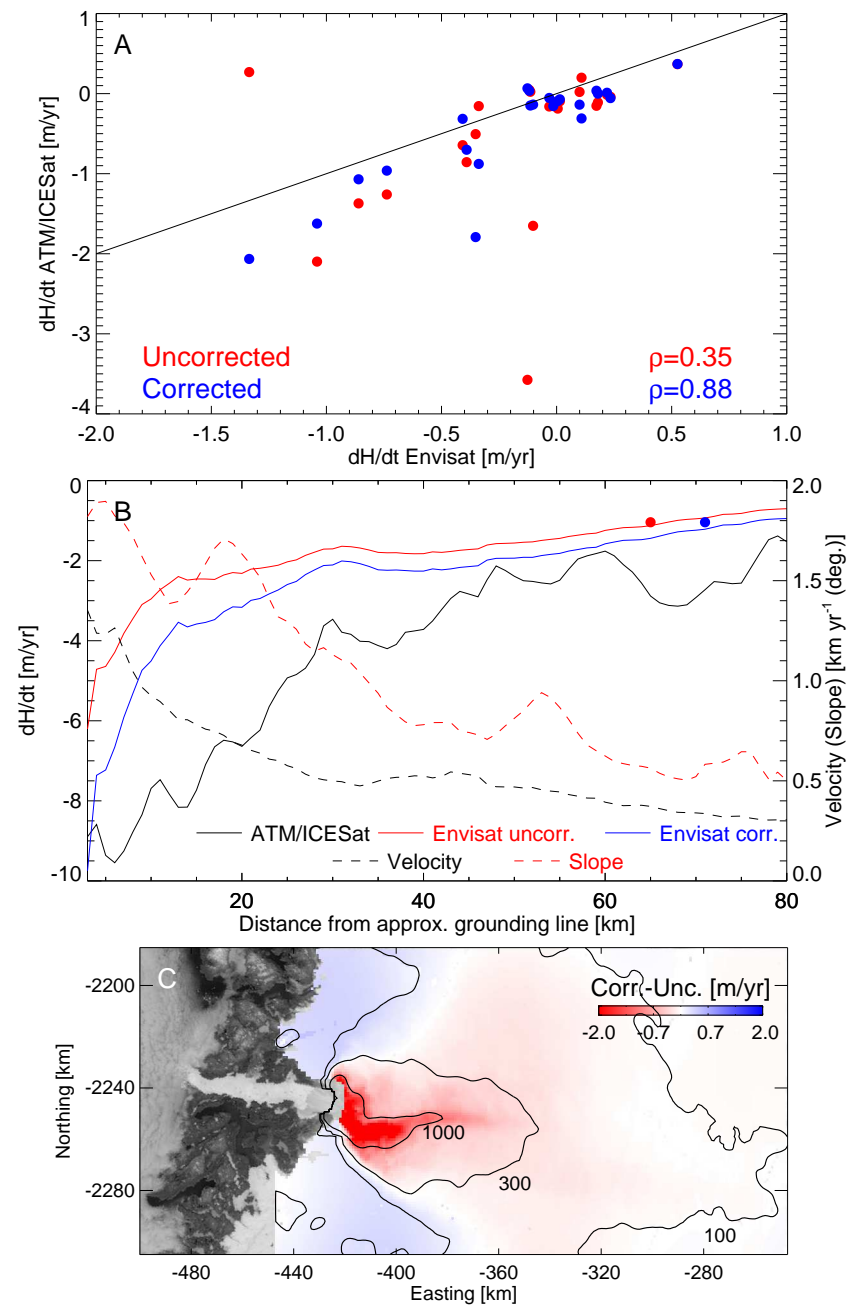

Fig. 3. Comparison of $\mathrm{d} H / \mathrm{d} t$ from Envisat, before and after slope correction. (A) shows $\mathrm{d} H / \mathrm{d} t$ from Envisat cross-over clusters versus interpolated $\mathrm{d} H / \mathrm{d} t$ from ATM/ICESat at the corresponding locations. Red dots show uncorrected, blue dots corrected data. $\rho$ is the Pearson correlation coefficient for both cases. (B) shows interpolated $\mathrm{d} H / \mathrm{d} t$ along a transect inland from the grounding zone. All values along the transect are calculated as the north-south average within the $300 \mathrm{~m} \mathrm{yr}^{-1}$ velocity contour, and the asterisks indicate the (corrected and uncorrected) location of the only Envisat measurement in this area (Fig. 1). Also $\mathrm{d} H / \mathrm{d} t$ from ATM/ICESat and velocity are shown. (C) shows the difference between the interpolated $\mathrm{d} H / \mathrm{d} t$ based on Envisat, before and after correction. Negative values indicate higher values after correction, and velocity is shown as 100,300 , and $1000 \mathrm{~m} \mathrm{yr}^{-1}$ contours.

between the 100 and $300 \mathrm{~m} \mathrm{yr}^{-1}$ velocity contours (Fig. 1), with a more complete Envisat coverage, the equivalent error reduces from $-55 \%$ to $-44 \%$ (with respect to a volume loss of $6.6 \mathrm{~km}^{3} \mathrm{yr}^{-1}$ for ATM/ICESat). One explanation for the much larger volume changes for ATM/ICESat compared to Envisat is the better sampling by ATM/ICESat of regions affected by increased surface melt. This is not captured by the KED interpolation, which only accounts for dynamically induced $\mathrm{d} H / \mathrm{d} t$ (Hurkmans et al., 2012).

\section{Conclusions}

In deriving volume change estimates over the ice sheets, and from these mass change, from satellite radar altimetry, the effect of slope-induced error on the $\mathrm{d} H / \mathrm{d} t$ location is often ignored because the vertical error cancels out in repeat measurements, or the direct method is employed. The estimated $\mathrm{d} H / \mathrm{d} t$ values are, however, representative of locations further upslope than assumed, resulting in an underestimate of the volume change, and the elevation rate at the sub-satellite location. We show that this underestimation is substantial for an outlet glacier such as Jakobshavn Isbræ, where slopes can be up to $2^{\circ}$. For the fast flowing section of the catchment (where the density of the volume change is approximately that of ice) the error in volume change with respect to ATM/ICESat reduces from $-56 \%$ to $-42 \%$. Correcting for slope-induced error is a relatively straightforward procedure, but is important in deriving accurate ice sheet mass loss.

Acknowledgements. This work was supported by funding to the ice2sea programme from the European Union 7th Framework Programme, grant number 226375. Ice2sea contribution number 69. JAG was funded by the European Space Agency's Changing Earth Science network. We also thank C. Davis (University of Missouri), W. Krabill (NASA GSFC), L. Sandberg-Sørensen (DTU Space, Copenhagen) and I. Joughin (University of Washington) for allowing access to their data.

Edited by: I. M. Howat

\section{References}

Bamber, J. L.: Ice sheet altimeter processing scheme, Int. J. Remote Sens., 15, 925-938, doi:10.1080/01431169408954125, 1994.

Bamber, J. and Gomez-Dans, J. L.: The accuracy of digital elevation models of the Antarctic continent, Earth Planet. Sc. Lett., 237, 516-523, doi:10.1016/j.eps1.2005.06.008, 2005.

Bamber, J. L., Ekholm, S., and Krabill, W. B.: A new, highresolution digital elevation model of Greenland fully validated with airborne laser altimeter data, J. Geophys. Res., 106, 67336745, 2001.

Brenner, A. C., Bindschadler, R. A., Thomas, R. H., and Zwally, H. J.: Slope-induced errors in radar altimetry over continental ice sheets, J. Geophys. Res., 88, 1617-1623, 1983.

Brenner, A. C., DiMarzio, J. P., and Zwally, H. J.: Precision and accuracy of satellite radar and laser altimeter data over the continental ice sheets, IEEE T. Geosci. Remote. Sens., 45, 321-331, doi:10.1109/TGRS.2006.887172, 2007.

Howat, I. M., Smith, B. E., Joughin, I., and Scambos, T. E.: Rates of southeast Greenland ice volume loss from combined ICESat and ASTER observations, Geophys. Res. Lett., 35, L17505, doi:10.1029/2008GL034496, 2008.

Hurkmans, R. T. W. L., Bamber, J. L., Sørensen, L. S., Joughin, I., Davis, C. H., and Krabill, W.: Spatio-temporal interpolation of 
elevation changes derived from satellite altimetry for Jakobshavn Isbræ, Greenland, J. Geophys. Res., in review, 2012.

Joughin, I., Howat, I. M., Fahnestock, M., Smith, B., Krabill, W., Alley, R. B., Stern, H., and Truffer, M.: Continued evolution of Jakobshavn Isbræ following its rapid speedup, J. Geophys. Res., 113, F04006, doi:10.1029/2008JF001023, 2008.

Joughin, I., Smith, B. E., Howat, I. M., Scambos, T., and Moon, T.: Greenland flow variability from ice-sheet-wide velocity mapping, J. Glaciol., 56, 415-430, 2010.

Krabill, W. B., Abdalati, W., Frederick, E. B., Manizade, S. S., Martin, C. F., Sonntag, J. G., Swift, R. N., Thomas, R. H., and Yungel, J. G.: Aircraft laser altimetry measurement of elevation changes of the Greenland ice sheet: technique and accuracy assessment, J. Geodyn., 34, 357-376, 2002.

Krabill, W., Hanna, E., Huybrechts, P., Abdalati, W., Cappelen, J., Csatho, B., Frederick, E., Manizade, S., Martin, C. , Sonntag, J., Swift, R., Thomas, R., and Yungel, J.: Greenland ice sheet: increased coastal thinning, Geophys. Res. Lett., 31, L24402, doi:10.1029/2004GL021553, 2004.

Li, Y. and Davis, C. H.: Decadal mass balance of the Greenland and Antarctic ice sheets from high resolution elevation change analysis of ERS-2 and ENVISAT radar altimetry measurements, in: Proceedings of International Geoscience and Remote Sensing Symposium, vol. 4, pp. 339-342, Boston, MA, 2008.
Moholdt, G., Nuth, C., Hagen, J.-O., and Kohler, J.: Recent elevation changes of Svalbard glaciers derived from ICESat laser altimetry, Remote Sens. Environ., 114, 2756-2767, doi:10.1016/j.rse.2010.06.008, 2010.

Pritchard, H., Arthern, R., Vaughan, D., and Edwards, L.: Extensive dynamic thinning on the margins of the Greenland and Antarctic ice sheets, Nature, 461, 971-975, doi:10.1038/nature08471, 2009.

Remy, F., Mazzega, P., Houry, S., Brossier, C., and Minster, J. F.: Mapping of the topography of continental ice by inversion of satellite-altimeter data, J. Glaciol., 35, 98-107, 1989.

Thomas, R., Davis, C., Frederick, E., Krabill, W., Li, Y., Manizade, S., and Martin, C.: A comparison of Greenland ice-sheet volume changes derived from altimetry measurements, J. Glaciol., 54, 203-212, 2008.

Zwally, H., Schutz, B., Abdalati, W., Abshire, J., Bentley, C., Brenner, A., Bufton, J., Dezio, J., Hancock, D., Harding, D., Herring, T., Minster, B., Quinn, K., Palm, S., Spinhirne, J., and Thomas, R.: ICESat's laser measurements of polar ice, atmosphere, ocean, and land, J. Geodynamics, 34, 405-445, 2002. 